\title{
Melanomatosis leptomeníngea
}

\section{Leptomeningeal melanomatosis}

Mujer de 39 años que acude a urgencias por un cuadro de cefalea occipital y cervicalgia de dos meses de evolución, con pérdida de visión. En la exploración presentaba signo de Babinski izquierdo y edema de papila bilateral. En el TC craneal se evidenciaba hidrocefalia tetraventricular y lesiones hiperdensas difusas por toda la corteza cerebral. En la RMN cerebral se evidencia infiltración leptomeníngea difusa, hiperseñal en secuencias $\mathrm{T1}$ sin contraste (figura 1). Se realizó biopsia cerebral abierta, donde macroscópicamente se observa infiltración por tejido patológico negruzco de las leptomeninges (figura 2). Los hallazgos de anatomía patológica fueron compatibles con melanoma.

El examen cutáneo, PET de cuerpo entero, rastreo Gammagráfico con Galio 67y TC toraco-abdomino-pelvico descartaron lesiones en otras localizaciones; confirmando el diagnóstico de melanomatosis leptomeníngea primaria.

El sistema nervioso central y las cubiertas meníngeas pueden afectarse por una gran variedad de lesiones melanóticas (meningioma pigmentado, schwannoma melanótico, melanosis difusa, melanocitoma maligno, etc.), incluyendo una variedad meníngea del melanoma maligno, denominada melanomatosis leptomeníngea primaria.

Se debe a la diseminación de los melanocitos neoplásicos a través de las leptomeninges y los espacios de VirchowRobin. El origen de estas células neoplásicas está en los melanocitos leptomeníngeos que derivan del neuroectodermo, como los melanocitos cutáneos.

El diagnóstico es complejo y se basa en los hallazgos clínico-radiológicos y la citología del LCR; y en raras ocasiones se realiza mediante biopsia cerebral La carcinomatosis meníngea, la oligodendrogliomatosis, la paquimeningitis hipertrófica, la amiloidosis y diversos cuadros infecciosos, pueden simular esta entidad.

El diagnóstico diferencial principal debe realizarse con el melanoma maligno metastático. El patrón de crecimiento de la melanomatosis meníngea suele ser más difuso, sin embargo, el diagnóstico de melanoma metastático se basa en los hallazgos clínicos de un melanoma primario extracerebral.

\section{Diagnóstico}

\section{Melanomatosis Leptomeníngea}

Julián Castro Castro, Alfonso Pinzón Millán

Servicio de Neurocirugía. Complexo Hospitalario Universitario de Ourense (CHOU). SERGAS. Ourense

Como citar este artículo: Castro Castro J, Pinzón Millán A

Melanomatosis Leptomeníngea. Galicia Clin 2012; 73 (3): 131

Recibido: 03/03/2012; Aceptado: 13/03/2012

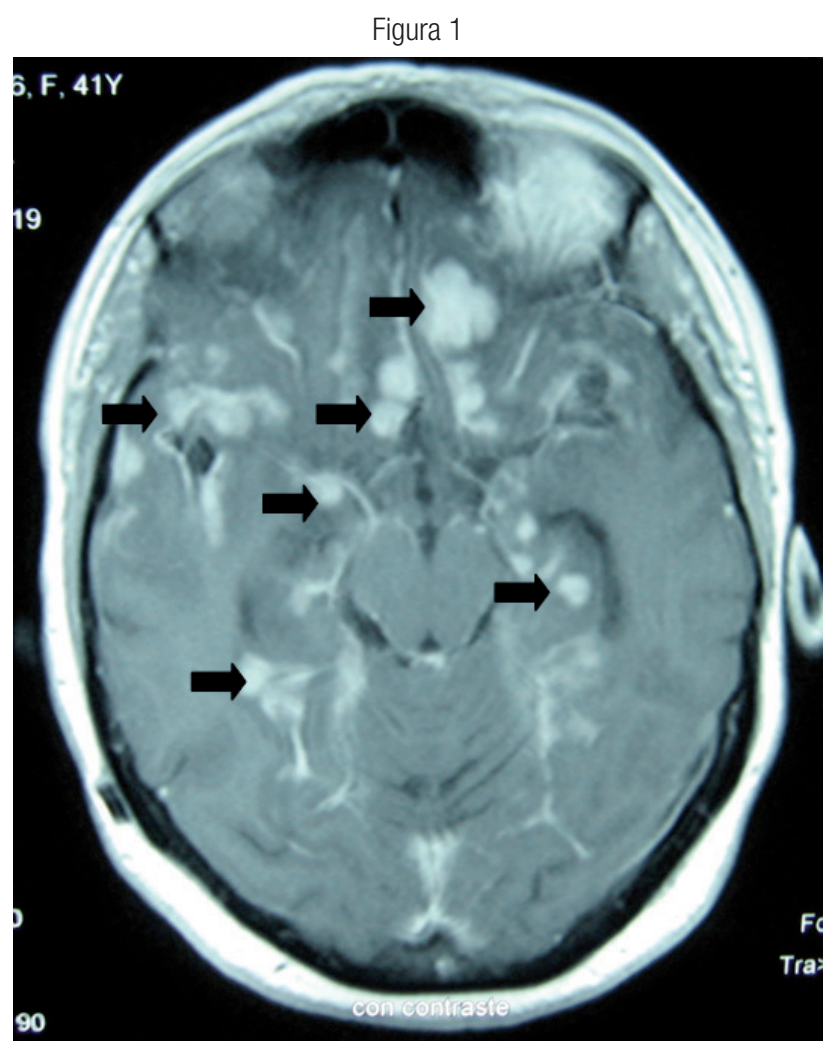

Figura 2

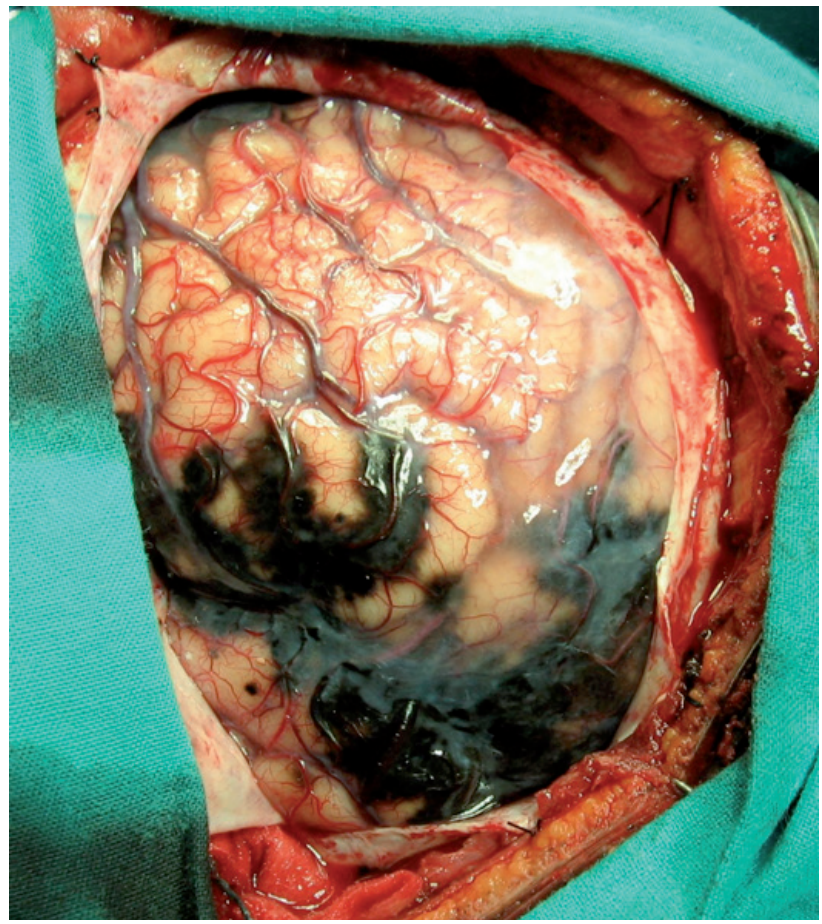

\section{Bibliografía}

1. Jaiswal S, Vij M, Tungria A, Jaiswal AK, Srivastava AK, Behari S. Primary melanocytic tumors of the central nervous system: a neuroradiological and clinicopathological study of five cases and brief review of literature. Neurol India. 2011; 59: 413-9.

2. Zadro I, Brinar W, Barun B, Ozretic D, Pazanin L, Grahovac G, Habek M. Primary diffuse meningeal melanomatosis. Neurologist. 2010; 16: 117-9. 